\title{
PENGEMBANGAN E-LEARNING BERBASIS MOODLE DI FAKULTAS KEGURUAN DAN ILMU PENDIDIKAN UNIVERSITAS MULAWARMAN
}

\author{
Mei Vita Romadon Ningrum ${ }^{1)}$ dan Dewi Rosita ${ }^{2)}$ \\ ${ }^{1}$ Program studi Pendidikan Geografi Jurusan Pendidikan MIPA FKIP Universitas Mulawarman \\ ${ }^{2}$ Program Studi Pendidikan Komputer Jurusan Pendidikan MIPA, FKIP Universitas Mulawarman \\ 1,2Jl. Muara Pahu Kampus Gunung Kelua Samarinda \\ E-mail: mei_vita88@yahoo.com ${ }^{1)}$,dew.rosita@gmail.com ${ }^{2)}$
}

\begin{abstract}
ABSTRAK
E-Learning merupakan proses pembelajaran dimana penyampaian materi, diskusi dan kegiatan perkuliahan lainnya dilakukan melalui media elektronik. Dukungan infrastrukur jaringan komputer di Fakultas Kegurun dan Ilmu Pendidikan Universitas Mulawarman (FKIP UNMUL) sangat mendukung untuk dikembangkan sarana belajar-mengajar berbasis eLearning. Oleh karena itu diperlukan pengembangan akan konten pada e-learning yang berbasis website tersebut. Moodle adalah perangkat lunak yang berguna untuk membuat dan mengadakan kursus, pelatihan dan pendidikan berbasis internet yang telah mendukung standar pendistribusian konten e-learning. Tujuan dari penelitian ini adalah (1) mengembangkan Elearning berbasis Moodle di FKIP UNMUL sehingga dapat memberikan tambahan waktu yang berkualitas di luar jam kuliah dan menjadi alat bantu perkuliahan untuk penyampaian materi, tugas-tugas terstruktur dan diskusi dari mata kuliah. (2) melakukan evaluasi dari pengembangan e-Learning berbasis Moodle pada Fakultas Keguruan dan Ilmu Pendidikan Universitas Mulawarman, Penelitian yang dilakukan adalah penelitian pengembangan dengan menggunakan model Waterfall. Pengujian pada sistem ini menggunakan pengujian blackbox dan whitebox. Hasil dari pengembangan e-learning ini adalah portal e-learning dengan nama E-Learning FKIP Universitas Mulawarman yang dapat diakses secara online melalui alamat https://elearningfkipunmul.com/. Hasil evaluasi menunjukan bahwa selama penelitiaan telah menunjukan hasil umpan balik (feedback) dari pengguna e-learning ini sudah pada kriteria BAIK dengan presentase sebesar $81 \%$. Penelitian baru sampai pada tahap pengembangan e-learning, sehingga perlu diadakan penelitian lanjutan untuk penelitia tindakan kelas. Paket konten disusun berupa teks dan flash presentation, sehingga perlu dikembangkan untuk tipe lain seperti video on demand maupun video streaming. Perlu diadakan penelitian lanjutan untuk penerapan Knowledge Management Sytem pada E-Learning
\end{abstract}

Kata Kunci: Pengembangan, E-Learning, Moodle, Waterfall, Universitas Mulawarman

\section{PENDAHULUAN}

Teknologi baru terutama dalam bidang ICT memiliki peran yang semakin penting dalam pembelajaran. Multimedia akan dapat membawa kita kepada situasi belajar dimana "learning with effort" akan dapat digantikan dengan "learning with fun". Dalam pembelajaran orang dewasa ( andragogi) learning with effort menjadi hal yang cukup menyulitkan untuk dilaksanakan karena berbagai faktor pembatas seperti usia, kemampuan daya tangkap, kemauan berusaha, dan lain lain. Jadi proses pembelajaran yang menyenangkan, kreatif, tidak membosankan menjadi pilihan para fasilitator.

Salah satu pemanfaatan internet adalah pada sistem pembelajaran secara elektronik atau yang lebih dikenal dengan istilah e-learning. e-learning merujuk pada penggunaan teknologi internet untuk mengirimkan serangkaian solusi yang dapat meningkatkan pengetahuan dan keterampilan (Rosenberg: 2001). Selain itu e-learning didefinisikan sebagai berikut: "e-learning is instruction delivered on a computer by way of $C D$ ROM, Internet, or intranet" (Menurut Clark \& Mayer (2008: 10) artinya $e$ - learning merupakan suatu jenis system pembelajaran yang memungkinkan tersampaikannya bahan ajar ke peserta didik dengan menggunakan media internet, intranet atau media jaringan komputer lain. Sedangkan menurut Horton (2001, p. 1) "E-learning is the use of electronic technologiest create learning experiences". Berdasarkan definisi tersebut, dapat disimpulkan bahwa e-learning dibuat agar pembelajaran dapat berlangsung lebih terbuka dengan berbagai cara seperti merumuskan, mengorganisir, dan menciptakan pengalaman belajar yang lebih bebas, pembelajaran elektronik juga bertujuan keberhasilan pembelajaran, dimana didalamnya terdiri dari kombinasi elemen-elemen antara informasi, interaksi dan komunikasi pendidikan

Saat ini e-learning sudah banyak diterima oleh masyarakat dunia, terbukti dengan maraknya implementasi di lembaga pendidikan (sekolah, training dan universitas) maupun industri (Cisco System, IBM, $\mathrm{HP}$, Oracle, dan lainya). E-learning E-learning adalah proses learning (pembelajaran) menggunakan atau memanfaatkan Information and Communication Technology (ICT) sebagai tools yang dapat tersedia kapanpun dan dimanapun dibutuhkan, sehingga dapat mengatasi kendala ruang dan waktu ( Darmawan; 2014) . E-Learning memberikan harapan baru sebagai alternatif 
solusi atas sebagian besar permasalahan pendidikan di Indonesia, dengan fungsi yang dapat disesuaikan dengan kebut uhan, baik sebaga suplemen (tambahan), komplemen (pelengkap), ataupun subsitusi (pengganti) atas pembelajaran di dalam kelas. Moodle adalah suatu Course Content Management (CMS), yang diperkenalkan pertama kali oleh Martin Dougiamas, seorang computer scientist dan educator yang menghabiskan waktunya untuk mengembangkan sebuah Learning Management System di salah satu perguruan tinggi di Kota Perth, Australia. Moodle memberikan suatu inspirasi bagi pengembangan e-learning. Moodle merupakan akronim dari Modular Object Oriented Dynamic Learning Environtment. Moodle didesain untuk mendukung kerangka konstruksi sosial dalam pendidikan dan termasuk dalam model CAL+CAT (Computer Assisted Learning + Computer Assisted Teaching). Moodle merupakan sebuah CMS yang berbasis open source yang saat ini digunakan oleh universitas, lembaga pendidikan, Sekolah, bisnis dan instruktur individual yang ingin menggunakan teknologi web untuk pengelolaan kursusnya (Cole: 2005). Moodle dalam pembelajaran sains banyak digunakan sebagai salah satu media pembelajaran karena membantu dalam mengajar sains. Hartanto dan Purbo (2005) menyatakan bahwa ada beberapa alasan menggunakan moodle untuk meningkatkan pengajaran, yaitu: (1) mampu memberikan siswa akses ke bahan kursus dalam lingkungan yang terkendali sehingga pembelajaran dapat berlangsung dimana saja; (2) memantau kemajuan dan menyimpan catatan belajar siswa; (3) memperluas kelas dengan menyediakan diskusi online, evaluasi, kegiatan, dan yang paling penting memungkinkan kolaborasi serta komunikasi untuk pembelajaran; (4) memanfaatkan multimedia yang menarik, media 3D interaktif, dan konten berbasis web yang memungkinkan siswa dengan gaya belajar yang berbeda untuk mengakses kurikulum; dan (5) membantu pendidik sains berkolaborasi, berbagi, dan menyimpan sumber daya pengajaran.

Berdasarkan observasi yang telah dilakukan di Fakultas Keguruan dan Ilmu Pendidikan Universitas Mulawarman ( FKIP UNMUL) menunjukkan bahwa hampir semua dosen tidak memiliki e-learning dalam menunjang pembelajarannya. Kegiatan perkuliahan dilakukan secara konvensional melalui tatap muka dan praktikum, padahal dukungan infrastrukur jaringan komputer di FKIP UNMUL sangat mendukung untuk dikembangkan sarana belajar-mengajar berbasis $e$ Learning. Oleh karena itu diperlukan pengembangan akan konten pada e-learning yang berbasis website tersebut. Dalam sistem e-learning dapat melakukan upload materi perkuliahan, membuat soal/ kuis, membuat forum diskusi dan pengelolaan/ manajemen mahasiswa. Diterapkannya pembelajaran melalui tatap muka dan pembelajaran online dengan e-learning akan membentuk sistem pembelajaran blended learning yang menggabungkan antara sistem pembelajaran konvensional melalui tatap muka dan system pembelajaran kelas virtual melalui e-learning. Dengan adanya inovasi pembelajaran secara online ini diharapkan dapat meningkatkan efektifitas dalam perkuliahan.

\section{RUANG LINGKUP}

Untuk memperjelas masalah yang akan dibahas dan agar tidak terjadi pembahasan yang meluas dan menyimpang maka perlu kiranya dijelaskan ruang lingkup pada penelitian ini. Adapun ruang lingkup dalam penelitian ini adalah bagaimana mengembangkan $E$ learning dengan menggunakan Learning Managemnet System (LMS) yaitu Moodle pada Fakultas Keguruan dan Ilmu Pendidikan Universitas Mulawarman. Elearning yang di bangun dengan menggunakan hosting pada domain Fakultas Keguruan dan Ilmu Pendidikan Universitas Mulawarman. Hasil penelitian ini akan membantu dosen untuk memperbaiki kualitas pembelajaran, menjadikan pembelajaran lebih efektif.

\section{BAHAN DAN METODE}

Penelitian ini menggunakan prosedur Research and Development ( R\& D). Untuk pengembangan sistem penelitian ini menggunakan model SDLC (Software Development Life Cycle). SDLC adalah proses pembuatan dan pengubahan system serta model dan metodologi yang digunakan untuk mengembangkan sebuah system. Model Waterfall adalah pendekatan SDLC paling awal yang digunakan untuk pengembangan perangkat lunak. Model Waterfall menggambarkan proses pengembangan perangkat lunak dalam aliran sekuensial linier. Ini berarti bahwa setiap tahap dalam proses pembangunan dimulai hanya jika tahap sebelumnya selesai. Dalam model waterfall ini, fase tidak tumpang tindih. Pengembangan produk dengan model waterfall terdiri 6 tahapan yaitu : 1) requirement analysis; 2) system desain; 3) implementation; 4) tesing; 5) deployment; 6) maintenance.

Model pengembangan yang digunakan pada penelitian ini yaitu dengan menggunakan model waterfall. Adapun tahapan dalam model tersebut adalah :

1. Analisis Kebutuhan Sistem

Pada tahap ini dilakukan observasi dan wawancara. Tahap ini menganalisis kondisi SDM, kondisi pembelajaran yang sedang berjalan saat ini, menganalisa infrastruktur dan proses pembelajaran saat ini dalam kaitanya dengan penerapan e-learning.

2. Desain Sistem

Desain sistem merupakan gambaran dari analisis kebutuhan. Desain sistem pengembangan e-learning meliputi : user interface, basis data (database) hingga rancangan pengodean yang dilakukan. Pada tahap desain ini dibuat spesifikasi secara rinci mengenai proyek, gaya, dan kebutuhan materi untuk produl yang akan dikembangkan. Dalam merancang atau mendesain produk dilakukan melalui dua tahap, yaitu : Memilih dan menetapkan software/perangkat lunak yang akan digunakan dan Mengembangkan 
flowchart, program mapping dan storyboard untuk menvisualisasikan alur kerja produk mulai dari awal hingga akhir.

3. Implementasi (Implementation)

Merupakan porses yang dilakukan untuk mewujudkan desain menjadi kenyataan dengan mengikuti alur proses pengodeaan. Pada tahap ini menghasilkan unit-unit produk sesuai dengan desain yang telah dibuat pada tahap sebelumnya. Unit-unit produk yang dihasilkan juga dilakukan pengujian(unit testing) sebelum nantinya digabungkan pada tahap selanjutnya.

4. Pengujian (Testing)

Dilakukan pengabungan unit-unit produk yang dihasilkan pada tahap sebeumnya menjadi produk lengkap. Paha tahap ini juga dilakukan pengujian produk yang dihasilkan/dikembangkan sudah diuji. Pentingnya pengujian perangkat lunak dan implikasinya yang mengacu pada kualitas perangkat lunak tidak dapat terlalu ditekan karena melibatkan sederetan aktivitas produksi dimana peluang terjadinya kesalahan manusia sangat besar dank arena ketidakmampuan manusia untuk melakukan dan berkomunikasi dengan sempurna maka pengembangan perangkat lunak diringi dengan aktivitas jaminan kualitas, dimana software yang dibuat diuji apakah sudah memenuhi kebutuhan atau belum. Tahap Pengujian ini dibagi menjadi dua yaitu : blackbox dan whitebox

5. Penyebaran sistem

Setelah sistem selesai dalam tahap pengujian, sistem disebarkan/ diaplikasikan kepada pengguna dengan harapan dapat mencapai tujuan dalam pengembangan produk

6. Perawatan (Maintenamce)

Sistem akan diperbaiki dan disempurnakan lagi dengan melakukan revisi sesuai dengan masalah yang muncul ketika produk digunakan pada lingkungan pengguna ataupun memastikan semua komponen sistem masih tetap berfungsi. Pemeliharaan ini termasuk juga memperbaiki kesalahan yang tidak ditemukan pada langkah sebelumnya.

Dalam rangka pengumpulan data yang diperlukan oleh suatu kegiatan penelitian, beberapa teknik yang digunakan. Proses pengumpulan data dengan menggunakan teknik yang salah tidak akan menghasilkan data yang maksimal sesuai dengan yang diperlukan pada penelitian. Teknik pengumpulan data yang dianggap tetap dalam penelitian ini adalah Observasi, Studi Literatur, Kuesioner. Pada pengumpualan data kuesioner adalah melakukan evaluasi untuk mendapatkan umpan balik pengguna. subjek dari evaluasi ini adalah dosen FKIP Unmul. Metode pengambilan sampel menggunakan metode acar sederhana (simple random sampling), yaitu metode yang digunakan untuk memilih sampel dari populasi dengan cara sedemikian rupa sehingga setiap anggota populasi mempunyai peluang yang sama besar untuk diambil sebagai sampel (Sugiarto, 2001).

Penelitian ini menggunkan angket sebagai teknik pendukung untuk mengevaluasi respon pengguna. setelah penentuan indicator, maka selanjutnya dilakukan pembuatan kisi-kisi yang akan digunakan sebagai pedoman dalam pembuatan pertanyaan pada angket. Angket menggunakan format respon 4 poin dari skala likert yang alternative responnya adalah Sangat Setuju (SST), Setuju (ST), Tidak Setuju (TS) dan Sangat Tidak Setuju (STS). Penentuan skor skala likert dilakukan secara apriori. Bagi skala yang berarah positif akan mempunyai kemungkinan-kemungkinan skor 4 untuk respon SST, skor 3 untuk respon ST, skor 2 untuk respon TS, dan skor 1 untuk respon STS. Adapun indikator yang dipergunakan dalam mengevaluasi $e$ - learning yang telah dikembangkan ditampilkan pada tabel 1 .

Tabel 1. Kisi-Kisi Angket

\begin{tabular}{|l|c|}
\hline \multicolumn{1}{|c|}{ Indikator } & Soal Nomor \\
\hline User satisfaction (kepuasan pengguna) & 4,5 \\
\hline Usability (kemudahan dalam penggunaan) & 6,10 \\
\hline Graphic design (tampilan desain grafis) & $9,11,15$ \\
\hline Navigation (sistem navigasi) & 7 \\
\hline Content (isi materi) & $1,2,3,8$ \\
\hline Individual impact (pengaruh terhadap individu) & $13,12,14$ \\
\hline
\end{tabular}

Analisis data dilakukan untuk mengetahui hasil evaluasi. Pada penelitian ini tidak melihat aspek statistiknya secara mendalam, sehingga data dianalisis dengan sistem deskriptif presentase. Untuk penyajian data deskriptif tersebut dijelaskan dalam bentuk persentasi dengan rumus (1):

$$
P=\frac{n}{N} \times 100 \%
$$

Keterangan (1)

$\mathrm{P}=$ Persentase sub variabel

$\mathrm{n}=$ Jumlah nilai tiap sub variabel

$\mathrm{N}=$ Jumlah skor maksimum

Langkah selanjutnya setelah diperoleh persentase pada sub variabel indikator adalah menganalisis dengan mengkonsultasikan dengan tabel range persentase dan kriteria sistem yang untuk mendapatkan kriteria berikut ini (tabel 2):

Tabel 2. Range Persentase dan Kriteria Kualitatif Sistem

\begin{tabular}{|c|c|c|}
\hline No & Interval & Kriteria \\
\hline & $76 \%<$ skor $\leq 100 \%$ & Baik \\
\hline & $51 \%<$ skor $\leq 75 \%$ & Cukup \\
\hline & $26 \%<$ skor $\leq 50 \%$ & Kurang Baik \\
\hline & $0 \%<$ skor $\leq 25 \%$ & Tidak Baik \\
\hline
\end{tabular}




\section{PEMBAHASAN}

Penelitian ini telah menghasilkan sebuah portal elearning dengan nama E-Learning FKIP Universitas Mulawarman yang dibangun dengan menggunakan LMS open source Moodle dan dapat diakses secara online pada alamat https://elearningfkipunmul.com/.

Portal e-learning yang telah dibuat berdasarkan hasil analisis kondisi SDM, infrastruktur, dan kondisi pemebalajaran saat ini. Pengembangan portal e-learning menggunakan MOODLE versi 3.0+ dengan menggunakan tema adptable. Sebelum melakukan instalasi pada server hosting maka dilakukan instalasi prototype dengan tujuan agar portal yang diimplementasikan nantinya dapat dipastikan berjalan dengan baik. Instalasi prototype dilakukan pada server local menggunakan paket XAMPP 3.2.2 dengan spesifikasi data server PHP 5.6.31, Apache 2.4.26, MariaDB 10.1.25 dan OS Win 7.

Desain tampilan Moode dimodifikasi semenarik mungkin dengan menggunakan tema yang telah tersedia pada http://moodle.org sehingga pengguna merasa nyaman dalam menggunakan portal e-learning. Pada halaman muka dibuat menu kategori jurusan dan tampilan course terbaru yang telah diupload oleh dosen. Gambar 3 menunjukan tampilan halaman muka dari portal $e$-learning.

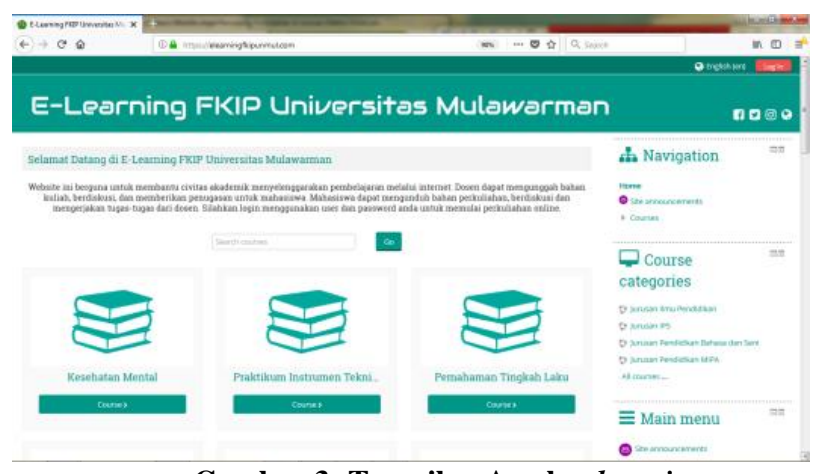

Gambar 3: Tampilan Awal e- learning

Agar mudah diakses pengguna, portal $e$ learning dibuat kategori sesuai dengan jurusan, setelah itu dibuat sub kategori program studi sesuai dengan jurusan masing-masing. Dalam sub kategori program studi terdapat sub-sub kategori nama-nama dosen sesuai dengan homebase dosen masingmasing pada program studi. Setiap dosen dapat mengupload materi, memberikan kuis serta dapat membuat forum diskusi sesuai dengan mata kuliah yang diampu. Tampilan e-learning yang dimaksud dapat dilihat pada gambar 3 berikut ini:

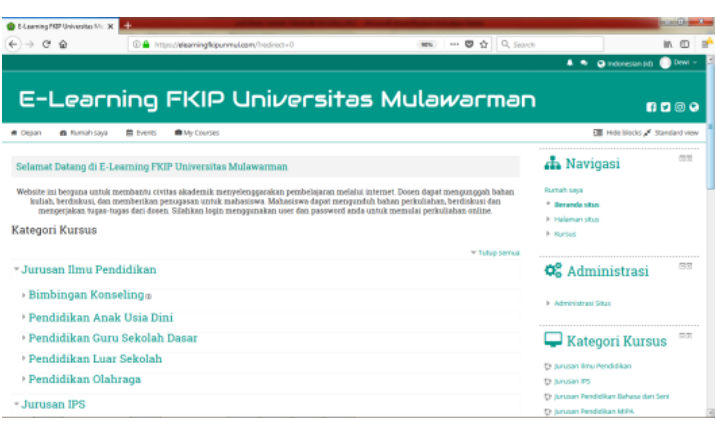

Gambar 3: Tampilan menu kategori jurusan

Pada tahap pengujian ini menggunakan metode blackbox dan whitebox. Untuk blackbox digunakan pada pengujian terhadap user (dosen) sedangkan untuk admin menggunakan metode pengujian whitebox. Blackbox testing adalah pengujian yang dilakukan oleh pengguna dari aplikasi yang dibuat yg dilakukan sebagai user. Pengujian ini menggunakan blackbox yang mana pada tahap ini dilakukan pengujian sebagai user. Whitebox testing adalah pengujian yang dilaksanakan oleh programmer dari aplikasi. Tujuan dari whitebox testing adalah untuk menjaga integritas dari kode program (menjamin hasil keluar sesuai dengan hasil harapan), tanpa melihat interaksi dari pengguna. Pada tahap ini dilakukan oleh user sebagai admin, tahap ini menggunakan metode pengujian whitebox.

Untuk mendapatkan umpan balik berupa tanggapan dalam mengoperasikan produk e- learning yang dikembangkan sehingga dapat dijadikan evaluasi dari pengembangan model pembelajaran e-learning, peneliti memberikan kuesioner kepada user. Dari analisa kuesioner dihasilkan kriteria BAIK dengan persentase skor $80 \%$ untuk indikator user satisfaction, sehingga dapat diketahui bahwa secara umum pengguna merasa senang dan tertarik dengan sistem pembelajaran elearning. Dalam aspek kemudahan mengakses/ mengupload materi juga menentukan terhadap baik atau tidaknya sebuah paket pembelajaran e-learning ini. Berdasarkan hasil analisa kuesioner didapatkan skor analisis sebesar 79\% dengan kriteria BAIK, sehingga dari usability pengguna merasa mudah untuk mempelajari penggunaan portal dan tingkat frekuensi kesalahan yang ditimbulkan oleh sistem dalam kategori kecil.

Design grafis merupakan factor penting karena berkenaan dengan kepuasan visual user sebagai subyektif. Pada hasil analisis diketahui bahwa bahwa secara design grafis portal e-learning termasuk dalam kategori BAIK, karena pengguna merasa puas dan merasa mudah untuk menggunakan sebagai bahan ajar dengan persentase $80 \%$. Sedangkan dari segi navigation didapatkan presentase $77 \%$ dengan kriteria BAIK.

Konten atau isi materi pembelajaran harus disesuaikan dengan Satuan Acara Pembelajaran (SAP) yang telah disusun oleh setiap program studi. Hasil analisis kuesioner menunjukan bahwa $85 \%$ respon menyatakan konten yang disediakan dengan kriteria 
BAIK yaitu dapat upload materi, membuat tugas, membuat forum dan pemberian nilai dari model pembelajaran e-learning. Analisa terhadap factor Individual Impact (pengaruh terhadap individu). Pada kategori ini didapatkan presentase $83 \%$ yang menunjukan bahwa pengguna termotivasi untuk menggunakan model pembelajaran e-learning ini disamping itu pula dengan adanya model pembelajaran e-learning dapat membantu menyelesaikan permasalahan yang dihadapi selama mengikuti perkuliahan tatap muka. Melalui model pembelajaran e-learning ini juga membantu pengguna untuk semakin cepat tanggap terhadap perkembangan teknologi khususnya dalam dunia pendidikan.

\section{KESIMPULAN}

Pengembangan sistem berupa e-learning dalam ini dibangun dengan menggunakan model waterfall. Hasil dari pengembangan e-learning di Fakultas Keguruan dan Ilmu Pendidikan Universitas Mulawarman adalah portal e-learning dengan nama E-Learning FKIP Universitas Mulawarman yang dapat diakses secara online melalui alamat https://elearningfkipunmul.com/. Sistem yang dibangun menggunakan pengujian blackbox dan whitebox. Hasil evaluasi menjukan bahwa selama penelitiaan telah menunjukan hasil umpan balik (feedback) dari pengguna e-learning ini sudah pada kriteria BAIK dengan presentase sebesar $81 \%$.

\section{SARAN}

Penelitian baru sampai pada tahap pengembangan $e$ learning, sehingga perlu diadakan penelitian lanjutan untuk penelitian tindakan kelas. Paket konten disusun berupa teks dan flash presentation, sehingga perlu dikembangkan untuk tipe lain seperti video on demand maupun video streaming. Perlu diadakan penelitian lanjutan untuk penerapan Knowledge Management Sytem pada E-Learning.

\section{DAFTAR PUSTAKA}

Clark, R. C., \& Mayer, E. R. 2008. Elearning and the science of instruction: provenguidelines for consumers and designers of multimedia learning (3rd ed.). San Francisco: Pfeiffer

Deni Darmawan. 2014. Pengembangan E-Learning Teori dan Desain. PT. Remaja Rosdakarya: Bandung

Gilbert, \& Jones, M. G. 2001. E-learning is e-normous. Electric Perspectives, 26(3), 66-82

Hartanto, A.A dan Purbo, O.W. 2005. Teknologi ELearning Berbasis php dan mysql, Jakarta: Elek Media Komputindo.

Heru Suhartanto. 2010. Strategi Implementasi Sistem ELearning untuk Peningkatan Mutu Pendidikan Sekolah Indonesia. Artikel Ilmiah. Fakultas Ilmu Komputer. Universitas Indonesia.

Horton, W. 2001. E-learning by design. San Fransisco: Pfeiffer.
ILRT. 2005. Institute for learning \& research technology of Bristol University. Retrieved 7 October 2005, from http://www.ilrt.bris.ac.uk/projects/elearning

Rosenberg, M. J. 2001. E-learning: Strategies for delivering knowledge in the digital age. New York: McGraw-Hill.

Somantri, M. 2004. Implementasi e-Learning di Teknik Elektro FT Undip. Jurnal Transmisi. 8(2):28-30.

Surjono, Dwi Herman. 2013. Membangun Course ELearning Berbasis Moodle Edisi Kedua, UNY Press. 